\title{
Laser Ablation of Hard-Tissues: a Review
}

\author{
Gholamreza Shayeganrad* \\ Department of Biomedical Engineering, University of Basel, Switzerland
}

${ }^{*}$ Corresponding Author: Gholamreza Shayeganrad, Department of Biomedical Engineering, University of Basel, 4123 Allschwil, Switzerland; E-mail: gholamreza. shayeganrad@unibas.ch; shayeganrad@yahoo.com

Received: October 05, 2018; Accepted: October 15, 2018; Published: November 28, 2018;

\begin{abstract}
Laser machining of biological hard tissues is coming today the most common medical application of the laser in dentistry and osteotomy, mainly because of the ability to cut faster, less invasive, free incision geometry with a higher quality and less thermal damaging surrounding tissues than the competing processes. However, there are two main energy loss mechanisms which limit the efficiency achievable in depth; (i) growing heat diffusion from the increasing surface area of the incision, and (ii) increasing absorption and scattering of laser light by the debris which is confined in the depth of the ablated area. In this paper, the dependence of the main parameters of hard tissue ablation on the laser parameters is reviewed. Moreover, we have presented the methods to bypass the limitation of the incision depth in laser ablation hard tissue by long mid-infrared laser pulses.
\end{abstract}

Keywords: Er: YAG laser, CO2 laser, Er: YSGG laser, micro-lens array, thermo-mechanical ablation, laser osteotomy, incision depth.

\section{Introduction}

Laser machining hard-tissue such as drilling, cutting, slicing, sawing, milling, coring, and grinding are basic operations of orthopedics and trauma surgery. Using conventional tools like drills, saws, hammers, grinders, or burs osteotomes present significant limitations because of high mechanical load, high cutting temperature, poor accuracy, potential of damage to the surrounding tissues, high bleeding, and long operation time that make orthopedic surgery extremely complicated with the precision which is determined in part by the size and workspace of the tool. Indeed, undesirable physical or biological effects to the hard tissue apart from the material removal may result in severe mechanical trauma, long recovery and healing time, permanent impairment, pain and thermal damage to the adjacent remaining tissues [1-4]. Particularly, the main problem concerning hard tissue processing with invasive traditional orthopedic saws, blades or drills normally is generating substantial heat and raising temperature as well as non-smooth and non-precise cutting surface $[1,5]$. In addition, the choice of incision geometry drastically limits to straight cuts or large radii of curvature.

Zhang et al. [6] provided a comparison review on orthopedic surgery using piezosurgery and conventional tools. Although the state-of-the-art piezo-osteotome has been applied increasingly in orthopedic surgery mainly because of its tissue selectively cutting function obtained by different frequencies as well as much more precision compared to the conventional tools, however, it still presents low-grade cut precision compared with laser-assisted hard bone tissue ablation. Cut edges show poor histological sharpness with irregular cut lines and poor incision quality with bone debris in the cut surface [7].

The need for clean, narrow, sharp, and precise cut geometry in orthopedic surgery lead lasers with various wavelengths have been evaluated continually. Such precision cuts are hard to achieve with conventional mechanical tools which normally induce mechanical stress, mechanical trauma, vibration, carbonization, and sometimes massive bleeding [8]. The rising temperature without cooling water increases with increasing laser fluence linearly and distributes into the surrounding tissues exponentially [9]. The water spray limits the temperature rises induced in the tissue to less than $3^{\circ} \mathrm{C}$ [9]. Water not only helps to remove debris from the ablation site and acts as a cooling agent, but also determines the ablation of tissues for thermomechanical effect by means of microexplosion of the water itself.

Lasers in the near- to mid-IR are eminently suitable for nondestructive hard tissue ablation in laser surgery, mainly due to very strong absorption of this functional wavelength regime by minerals (hydroxyapatite) as well as water in hard tissue $[10,11]$. The small amount of water presented in tissue absorbs laser energy strongly and vaporizes locally to generate enough pressure and ablate the tissue surface based on the thermomechanical ablation process. Although, non-contact laser surgery presents several advantages such as effectively less damaging surrounding tissue, less pain, less swelling, less bleeding, eliminating trauma, better cutting quality, and high accuracy [12], however, the cut depth saturates and the ablation efficiency drops with increasing incision depth. This phenomenon is generally found in laser ablation of all kinds of materials. The trend is faster for Gaussian lasers with longer pulse width and smaller beam radius. There are two main energy loss mechanisms which limit the achievable depth in addition to the absorption and scattering of laser energy by water in water-assisted laser surgery. The first is the growing heat diffusion from the increasing surface area of the incision. The second is the absorption and scattering of laser light due to interaction of laser with the ejected ablation products (debris) which are more and more confined in the cut profile as the cut progresses deeper into the tissue and interact more and more even when pulse width is larger. 
The desired specifications of water-assisted hard tissue laser ablation vary a lot in terms of laser parameters. In order to perform minimally invasive laser machining, it is important to optimize laser parameters such that laser ablation be fast, ablation being sharp and precise, the procedure be quiet with minimal vibrations imposed on the treated tissue, and the amount of residual heat that remains in the tissue following laser irradiation being also minimal. Up to now, the most promising laser sources were found to be the $\mathrm{CO} 2$ laser $(9.6 \mu \mathrm{m}$ and $10.6 \mu \mathrm{m})$, the Er: YAG laser $(2.94 \mu \mathrm{m})$ and the Er, Cr: YSGG laser $(2.78 \mu \mathrm{m})$. Among them, the wavelength of the Er: YAG laser at $2.94 \mu \mathrm{m}$ coincides with the main spectral absorption peak of hydroxyapatite tissue and water $[13,14]$. This laser was first applied in dentistry. In contrast to many other lasers, the preparation of hard tissue like dentine, or enamel is possible with minimal thermal injury and higher cutting efficiency [8, 14-19].

In this paper, the effect of the main laser parameters on hard tissue laser ablation are reviewed. Moreover, we proposed a technique to bypass the limitation of the laser ablation in incision depth introduced to hard tissue laser ablation by long-pulsed mid-IR lasers. In this technique an array of rotational micro-lens which is combined with a normal lens focuses the laser light on the hard tissue sample to increase the ablation efficiency in incision depth by creating holes in laser beam and reducing the effect of interaction laser and debris and therefore ejecting debris with less interaction with laser light. Consequently, the absorption and scattering of the incoming laser light by the debris decreases even with rising cut depth and thereby most of the energy can reach the depth of the incision.

\section{Laser interaction with hard-tissues}

When a laser beam strikes on the surface of the tissue, a small fraction of the radiation is reflected according to the Fresnel equation and the remaining fraction is propagated into the tissue and undergoes absorption and scattering processes [20]. The laser energy penetrates into the hard tissue depth (normally a few microns) depending on the absorption and scattering by tissue. The optical response of the tissue is given by the Beer-Lambert law:

$$
F_{\lambda}(z)=(1-R) F_{\lambda}(0) \exp \left(-\mu_{e f f} z\right)
$$

where $F_{\lambda}(z)$ is the laser fluence in the tissue $\left[\mathrm{W} / \mathrm{cm}^{2}\right]$ at depth $\mathrm{z}$ and wavelength $\lambda ; F_{\lambda}(0)$ is the incident fluence $\left[\mathrm{W} / \mathrm{m}^{2}\right]$ at wavelength $\lambda ; \mathrm{R}$ is the Fresnel reflection coefficient, $\mathrm{z}$ is the penetration depth into the tissue $[\mathrm{cm}], \mu_{\text {eff }}=\mu_{\mathrm{a}}+\mu_{\mathrm{s}}$ is the effective attenuation coefficient [ $\mathrm{cm}^{-}$ ${ }^{1}$ ], where $\mu_{\mathrm{a}}$ is absorption coefficient, and $\mu_{\mathrm{s}}$ is scattering coefficient at the used wavelength.

In the visible range, the absorption by biological tissues is mainly due to specific pigments of the tissue, such as hemoglobin in red blood cells, melanin in skin, and rhodopsin in the retina. In bone, absorption is introduced by collagen, water and hydroxyapatite nanocrystals. However, in the short range of penetration depth, the effective scattering coefficient is much smaller than the absorption coefficient $\left(\mu_{\mathrm{s}}<<\mu_{\mathrm{a}}\right)$ and therefor scattering by tissue is negligible. The depth at which the irradiance drops to $1 /$ e level is called optical penetration depth, $d=1 / \mu_{\text {eff }}$. For instance, for compact human bone or tooth the penetration depth is limited to few microns in the mid- infrared spectral region near $3 \mu \mathrm{m}$ due to strong absorption by water. It is remarkable that absorption and scattering by biological tissues may change during laser exposure. For instance, carbonization, in particular, may increase the absorption. However, the occurrence of carbonization must be avoided during any kind of clinical surgery.

For a biomedical tissue surrounded by air, the Fresnel equation is described as:

$$
R=\frac{(1-n)^{2}+k_{\text {ext. }}^{2}}{(1+n)^{2}+k_{\text {ext. }}^{2}}
$$

where $\mathrm{n}$ is the refractive index and $\mathrm{k}_{\mathrm{ext}}$.is the extinction coefficient of the tissue. The absorption coefficient $\mu_{a}$ of the tissue can be connected to the extinction coefficient $\mathrm{k}_{\text {ext. }}$ and wavelength $\lambda$ by:

$$
\mu_{a}=\frac{4 \pi k_{\text {ext. }}}{\lambda}
$$

In general, absorption increases strongly by pulse duration and low intensity [21]. For polished human enamel, the reflectance at 9.6 $\mu \mathrm{m}$ and $10.6 \mu \mathrm{m}$ has measured to be $49 \%$ and $13 \%$, respectively, while human dentin reflects $17 \%$ and $9 \%$ at $9.6 \mu \mathrm{m}$ and $10.6 \mu \mathrm{m}$, respectively [22]. For hydroxyapatite $\left(\mathrm{n} \approx 1.530\right.$ and $\left.\mathrm{k}_{\text {ext. }} \approx 8 \times 10^{-3}\right)$ surrounded by air $(\mathrm{n}=1)$, the power reflectance at normal incidence can be obtained to be about $4 \%$.

Ultrashort pulses ( $<10 \mathrm{ps}$ ) have been shown to generate little thermal or mechanical damage. In general, thermal effects can be decreased by reducing the pulse duration $[23,24]$ or by using lasers with radiation wavelength in the UV range $[25,26]$. Lasers that produce a photothermal effect use prolonged energy exposure to facilitate an increase in chromophore temperature, which in turn leads to cellular vaporization. This type of laser-tissue interaction is what occurs during surgical, ablation, and hair removal using laser. The absorbed energy by biological tissue converts to heat. Thermal effects can be induced by either $\mathrm{CW}$ or pulsed laser radiation. This may lead to distortion or the destruction of a tissue volume. In biological tissues, absorption is mainly caused by either water molecules or macromolecules such as proteins and pigments. For instance, water strongly absorbs the Er: YAG wavelength at $2.94 \mu \mathrm{m}$ and thus water within the layer of tissue vaporizes to induce localized micro-explosions. Liquid water is a collection of polar molecules connected by hydrogen bonds. When water transfers from liquid to vapor, it expands quit a lot and therefore induces increase in pressure. The density of water vapor at $100{ }^{\circ} \mathrm{C}$ and atmospheric pressure is about a factor of 1600 less, and therefore water expands by a factor of 1600 when it turns into vapor at atmospheric pressure.

It is possible to control the temperature rise and limiting thermal damages to the predetermined target to minimize the spread of heat to adjacent tissues. A high heating causes an irreversible deformation of biological tissues and losing of protein function. In situations when a laser pulse width is shorter than thermal relaxation time of the tissue (e.g. delivering short laser pulses), the initial temperature distribution assuming no heat conduction can be given by [27]:

$$
\Delta T(z)=\frac{\mu_{a} Q_{0} e^{-\mu_{a} z}}{\rho c A},
$$


where $\Delta \mathrm{T}(\mathrm{z})\left[{ }^{\circ} \mathrm{C}\right]$ represents the one-dimensional temperature distribution, $\mathrm{z}$ is the depth $[\mathrm{cm}], \mathrm{A}$ is the area $\left[\mathrm{cm}^{2}\right], \mathrm{c}$ is specific heat $\left[\mathrm{mJ} / \mathrm{gr} .{ }^{\circ} \mathrm{C}\right], \rho$ is density of the tissue $\left[\mathrm{gr} / \mathrm{cm}^{3}\right]$, and $\mathrm{Q}_{\mathrm{o}}$ is the incident energy $[\mathrm{mJ}]$.

Biological tissues can also be etched or cut beautifully with a high lateral and depth resolution laser photoablation. Photoablation is the most recent light-tissue interaction to be exploited in microsurgery such as keratoplasty, angioplasty, and neurosurgery. The advantage of using UV light resides in the fact that the ablation is strictly confined to the volume that absorbs the energy. The presence of water, which is essentially non-absorbing in UV, does not affect significantly the cleanliness of the photoablative cut by UV laser. Nevertheless, the threshold of ablation is increased by wavelength $\left(100 \mathrm{~mJ} / \mathrm{cm}^{2}\right.$ at 193 and $500 \mathrm{~mJ} / \mathrm{cm}^{2}$ at $248 \mathrm{~nm}$ for the cornea tissue). Due to high absorption coefficient in UV of many materials, the laser energy is very densely absorbed at the surface and therefore ablation volume is very small. UV laser Photoablation has an advantage which does not damage the tissue.

$\mathrm{CO}_{2}$ lasers with wavelengths centered around $10 \mu \mathrm{m}$ and represent a cost effective alternative to UV lasers. Unlike UV lasers, IR laser ablation is a purely thermal process. The laser beam directly applies heat on the tissue which partially evaporates. They typically produce a clean cut structure, thanks to high absorbance in IR by hard tissues.

The photoablation rate (AR) can be assumed to be proportional to the difference between the laser fluence $F$ and the threshold fluence $F_{\text {th }}$ :

$$
A R=k\left(F e^{-\mu_{a} z}-F_{\text {th }}\right),
$$

where $\mu_{\mathrm{a}}$ is effective absorption coefficient, and $\mathrm{k}$ is the rate constant. Photoablation will take place if $\mathrm{F}>\mathrm{F}_{\mathrm{th}}$. The ablation depth $\mathrm{d}$, i.e. the depth at which $\mathrm{F}(\mathrm{z})=\mathrm{F}_{\mathrm{th}}$, should then be [20]:

$$
d \simeq \frac{1}{\mu_{a}} \ln \frac{F_{0}}{F_{\mathrm{th}}},
$$

It shows ablation depth increases logarithmic with laser fluence. Above the threshold of plasma generation, $\mathrm{F}_{\mathrm{p}}$, the ablation depth per pulse saturates due to the well-known phenomenon called plasma shielding. Thereby, all abundant energy dissipates to heat leading to additional thermal effects by means of nonradiative relaxation. Hence, the crucial parameter for differentiating photoablation and thermal interaction is the photon energy or laser wavelength.

For a Gaussian spatial beam profile with a $1 / \mathrm{e}^{2}$-beam radius $\left(\mathrm{w}_{0}\right)$, the measured diameters $\left(D=2 r_{a}\right)$ of the ablated areas are related to the threshold fluence $\mathrm{F}_{\text {th }}$ [28]

$$
F_{\text {th }}=F_{0} \exp \left(-2 r_{a}^{2} / w_{0}^{2}\right),
$$

where $F_{0}$ is the applied peak laser fluence. For laser pulses with a Gaussian spatial beam profile, the maximum irradiation fluence $F$ can be calculated from the irradiation pulse energy $\mathrm{E}_{\mathrm{p}}$ and the beam radius $\mathrm{w}_{0}$ :

$$
F_{0}=2 E_{p} / \pi w_{0}^{2}
$$

From Eq. (7), if the fluence $\mathrm{F}$ exceeds the ablation threshold fluence $F_{\text {th }}$, the squared diameters of the ablated area of the ablation crater is correlated as [29]:

$$
D^{2}=2 w_{0}^{2} \ln \left(F_{0} / F_{\mathrm{th}}\right),
$$

Substituting Eq. (8) into Eq. (9), we can obtain:

$$
D^{2}=A \ln \left(E_{p}\right)+B,
$$

where

$$
\begin{aligned}
& A=2 w_{0}^{2}, \\
& B=\pi w_{0}^{2} \ln \left(2 / \pi w_{0}^{2} F_{\text {th }}\right),
\end{aligned}
$$

Eqs. (10)-(12) show that the ablation threshold fluence and the radius of the laser beam waist could be calculated from fit parameters to squared diameter of the ablated areas and the corresponding incident laser pulse energy.

Plasma-mediated ablation makes use of high energy laser pulses to ionize molecules with the first few femtosecond of the pulses and induced nonlinear absorption. This process leads to ablate the tissues in sub-micrometer size with negligible heat damage to the surrounding tissues. When the laser intensity exceeds $10^{13}-10^{14} \mathrm{~W} /$ $\mathrm{cm}^{2}$ corresponding an electric field of $\sim 10^{8}-10^{9} \mathrm{~V} / \mathrm{cm}$ in the order of electric field of the bind electrons in molecules, ablation proceeds via ionizing molecules at the focus and producing bubble of plasma at the focus with a high concentration of electrons and ions. This intensity can be achieved, for instance, with $100 \mathrm{~nJ}, 100 \mathrm{fs}$ pulses focused into $1 \mu \mathrm{m}^{2}$ area.

The most important aspect of femotosecond laser pulses is that the laser pulses are significantly shorter than the time it takes for electrons to transfer their energy to the lattice via electron-phonon coupling. The laser-induced plasma then absorbs the laser energy very quickly, causing the rapid removal, or ablation, of the target tissue with negligible thermal issues.

The ablation threshold is affected by the laser pulse width, wavelength and pulse numbers, among other factors, and was reported to be $0.6-2.2 \mathrm{~J} / \mathrm{cm}^{2}$ for enamel and $0.3-1.4 \mathrm{~J} / \mathrm{cm}^{2}$ for dentin (see, e.g. $[30,31]$ and reference therein). For multiple pulse ablation, the decrease of the ablation threshold with an increasing number of pulses was observed. When a low laser fluence was applied, only a small proportion in the center of the laser spot could cause ablation. However, when the laser fluence is increased far beyond the ablation threshold $\left(\mathrm{F}_{\mathrm{th}}\right)$, a "plasma shielding" effect may take place. Lizerelli, et al. [32] observed a conventional ablation pattern with photo thermal effect for enamel using femtosecond laser with central wavelength of $800 \mathrm{~nm}$ and fluence of $13 \mathrm{~J} / \mathrm{cm}^{2}$ corresponding intensity of $\sim 1.8 \times 10^{14}$ $\mathrm{W} / \mathrm{cm}^{2}$. In this case, only part of the energy was enough to cause the ablation process. However, with a laser fluence of $32 \mathrm{~J} / \mathrm{cm}^{2}$ and average intensity of $191 \mathrm{~mW}$, a sharp edge or rim definition preserving the original characteristics of the enamel and a highly prismatic structure was observed [32]. In this case that the pulse width is of $70 \mathrm{fs}$ less than the vibration relaxation time of the crystalline net (photon relaxation time) of the enamel, is of $100 \mathrm{fs}$, there is no time for the energy dissipation to the lattice via electron-phonon coupling or heat. 


\subsection{Interaction with debris and depletes}

In the presence of particles with size of the order or larger than the incident light wavelength, such as a water droplet or debris in laser cutting hard-tissues, the Mie scattering becomes predominant. For large particles, forward Mie scattering is more probable than backward-direction scattering. Mie scattering efficiency is generally much bigger than the Rayleigh's one. In hard tissue laser ablation, debris range in size from a few tenths of nanometer to about a hundred micrometers. For a fixed wavelength, the attenuation due to molecular scattering is smaller than that of aerosol scattering. In other words, the Mie scattering losses can be much larger than the Rayleigh scattering losses if enough particles are presented, especially for large wavelengths.

The absorption and scattering coefficients of water sprays (i.e. cloud of non-uniform size water droplets) can be predicted with Mie scattering theory. The theory allows one to calculate absorption, scattering and extinction efficiency function of homogenous particles (droplets) in terms of non-dimensional size parameter $\chi(=2 \pi \mathrm{r} / \lambda)$ and complex index of reflection $n^{\prime}=n(\lambda)+i k(\lambda)$, where $r$ is the radius of a scattering spherical particle, and $\lambda=\lambda_{0} / \mathrm{n}$ is wavelength. Rayleigh scattering, Mie scattering, or Geometric scattering is dominant, when $\chi<<1, \chi \sim 1$, or $\chi>>1$, respectively. The scattering regimes for a single scattering sphere particle in ultraviolet, visible, and infrared regions is presented in Fig. 1.

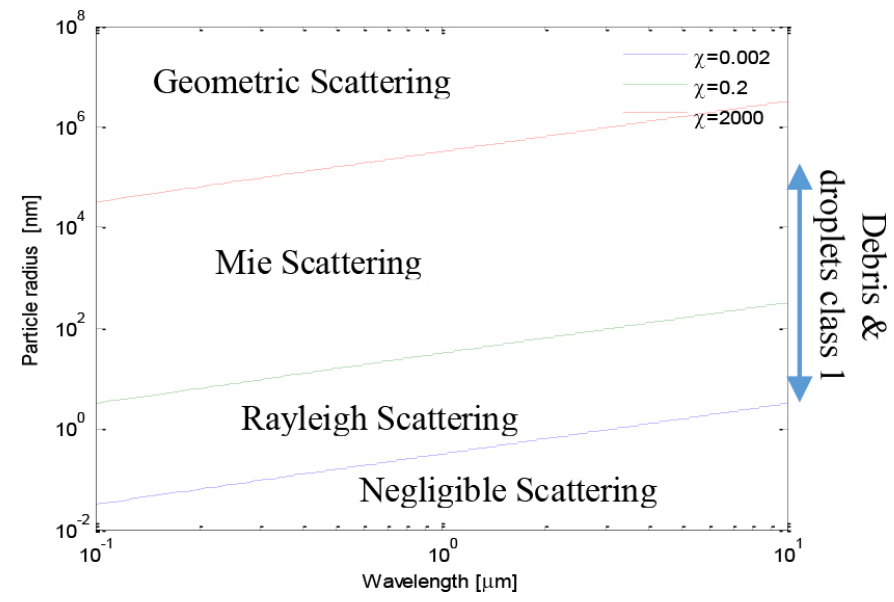

Fig. 1. The scattering regimes for a single scattering sphere particle. For details refer to the text.

Assuming that the particles have the same optical properties, the Mie total scattering cross section is expressed as the infinite series [33]:

$$
\sigma_{M}=\left(\frac{2 \pi}{k^{2}}\right) \sum_{n=1}^{\infty}(2 n+1)\left(\left|a_{n}\right|^{2}+\left|b_{n}^{2}\right|\right),
$$

where $k=2 \pi / \lambda$. The coefficients $a_{n}$ and $b_{n}$ are given by:

$$
\begin{aligned}
& a_{n}=\frac{\mu m^{2} j_{n}(m x)\left[x j_{n}(x)\right]^{\prime}-\mu_{1} j_{n}(x)\left[m x j_{n}(m x)\right]^{\prime}}{\mu m^{2} j_{n}(m x)\left[x h_{n}^{(1)}(x)\right]^{\prime}-\mu_{1} h_{n}^{(1)}(x)\left[m x j_{n}(m x)\right]^{\prime}}, \\
& b_{n}=\frac{\mu_{1} j_{n}(m x)\left[x j_{n}(x)\right]^{\prime}-\mu j_{n}(x)\left[m x j_{n}(m x)\right]^{\prime}}{\mu_{1} j_{n}(m x)\left[x h_{n}^{(1)}(x)\right]^{\prime}-\mu_{1} h_{n}^{(1)}(x)\left[m x j_{n}(m x)\right]^{\prime}}
\end{aligned}
$$

where the $\mathrm{j}_{\mathrm{n}}$ 's are spherical Bessel functions of the first kind, the $h_{n}$ 's are spherical Hankel functions, and $\mu_{1}$ and $\mu$ are the magnetic permeability of the sphere and surrounding medium, respectively. $\mathrm{m}=\mathrm{n}_{\mathrm{sph}} / \mathrm{n}_{\mathrm{med}}$ is the ratio of the refractive index of the particle to that of the surrounding medium. The series expression converges after a number of terms slightly larger than the size parameter. The normalized scattering cross-section, $\sigma / \pi \mathrm{r}^{2}$, versus size parameter, $\chi$, is shown in Fig. 2. The cross-section oscillators in the Mie scattering region and its maximum amplitude places at $\chi=1$. The oscillation is because of constructively and destructively interference of wave that reflects directly from the front surface of the sphere and creeping wave that travels around the back of the sphere. The corresponding Mie scattering cross-section is more complex than Rayleigh scattering with wavelength dependence proportional to $\lambda^{-\mathrm{x}}$, where $0.4<\mathrm{x}<0.5$.

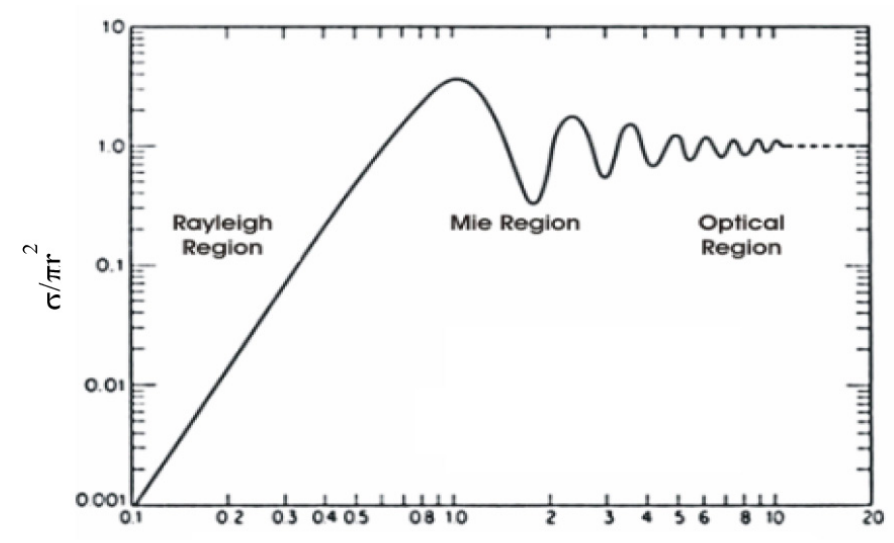

Size parameter, $\chi=2 \pi \mathrm{r} / \lambda$

Fig. 2. Normalized scattering cross-section versus size parameter, $\chi$ [34].

Generally, water is not opaque but semitransparent to radiation. However, for wavelengths greater than $2 \mu \mathrm{m}$ water becomes strongly absorbing, and large droplets are expected to be opaque to incident radiation for $\lambda>2 \mu \mathrm{m}$. Water sprays are of non-uniform size and the droplet size distribution depends on the design of the nozzles, water pressure for producing the water spray and the operation conditions. According to the size of the droplets, it can be divided to class $1,0 \leq$ $\mathrm{d} \leq 200 \mu \mathrm{m}$, class $2,200<\mathrm{d} \leq 500 \mu \mathrm{m}$, class $3,400<\mathrm{d}<1000 \mu \mathrm{m}$ in diameter.

It was already known that the interaction of laser light with ejected debris has a considerable influence on ablation characteristics of erbium lasers [35]. By using a quantum square pulse (QSP) chopped pulse Er: YAG mode (see Fig. 3) which was designed to reduce the temporal crossing of incoming laser radiation with ejected debris, it was possible to significantly increase dental enamel and cementum ablation drilling efficacy and reduce the rate of tissue desiccation. The appropriately timed chopped pulse structure of the QSP mode was shown to result in a high cutting efficacy and low thermal side-effects, a characteristic of short pulses, and in low vibrations and sharp cuts, which is a characteristic of longer pulses [35].

Ablation saturation was observed for all measured laser modes with the depth $\mathrm{d}_{\text {sat }}$ depending on the laser pulse duration (see Fig. 4.) The ablation saturation depth was measured to be largest for the QSP mode and decreases with increasing laser pulse duration. 

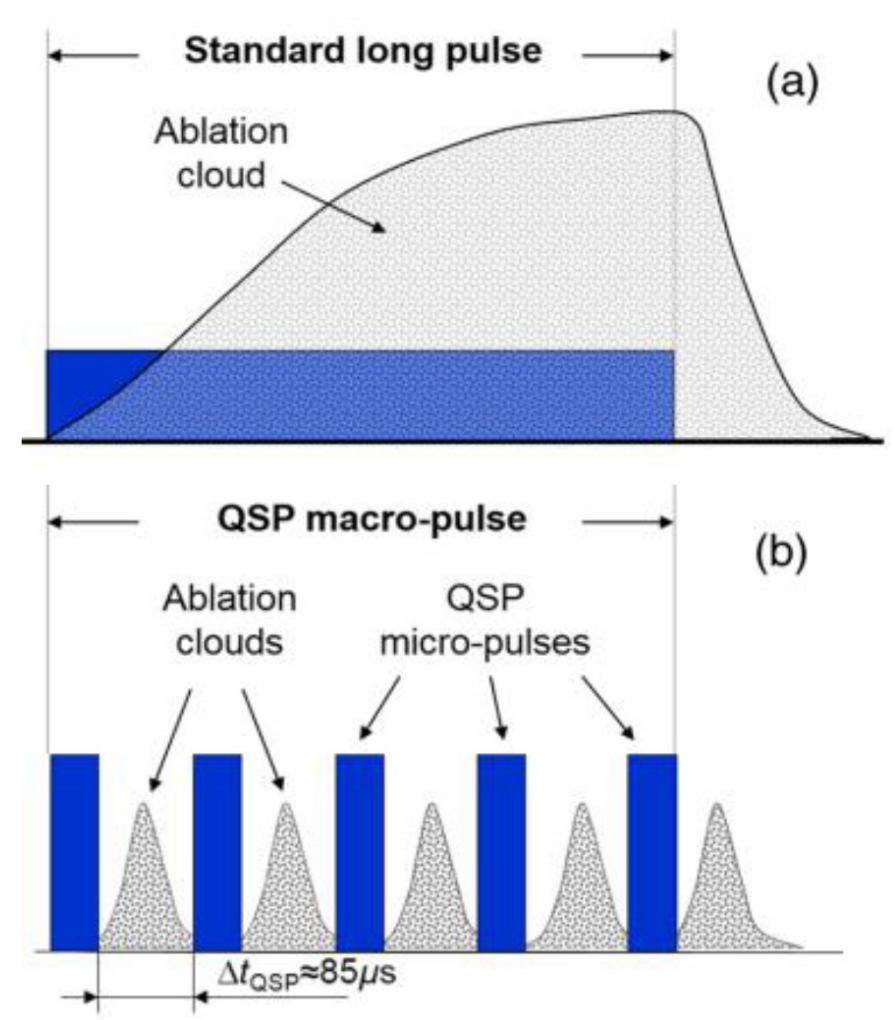

Fig. 3. a) Standard laser pulse; (b) QSP laser pulse. A 600- $\mu$ s macropulse is chopped into five micropulses with duration of $\mathrm{t}_{\mathrm{QSP}}=50 \mu \mathrm{s}$, and temporal spacing between the micropulses of $\Delta \mathrm{t}_{\mathrm{QSP}}=85 \mu \mathrm{s}$ [35].

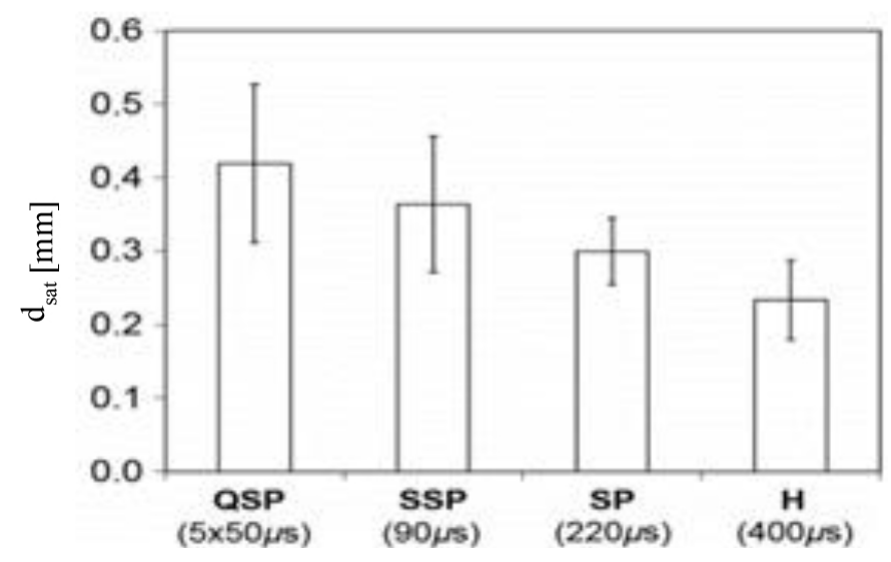

Fig. 4. Dependence of the ablation saturation depth $\left(d_{\text {sat }}\right)$ in enamel for different erbium laser pulse modes [35].

Although the ablation saturation depth and ablation efficiency was measured to be largest for the QSP mode, but chopper wheel which modulates the laser beam blocks the laser light and therefore reduces the ablation rate with decreasing energy per pulse. An alternative method to reduce the temporal cross-over of incoming laser radiation with ejected debris is combination of rotational micro-lens array with a normal lens ( see Fig. 5) which focuses the laser light on the hard tissue sample. The rotation velocity defines by distance between microlenses in array, velocity of ejection of debris and depth:

$$
\omega=\frac{l . v}{R . d}
$$

where $\mathrm{l}$ is distance between microlenses, $\mathrm{R}$ is distance of microlenses from center of the array, $\omega$ is angular frequency, and $\mathrm{v}$ is average of ejection velocity of debris. In this method, debris can be ejected from the cannels generated by lenslet without interaction with laser beam.
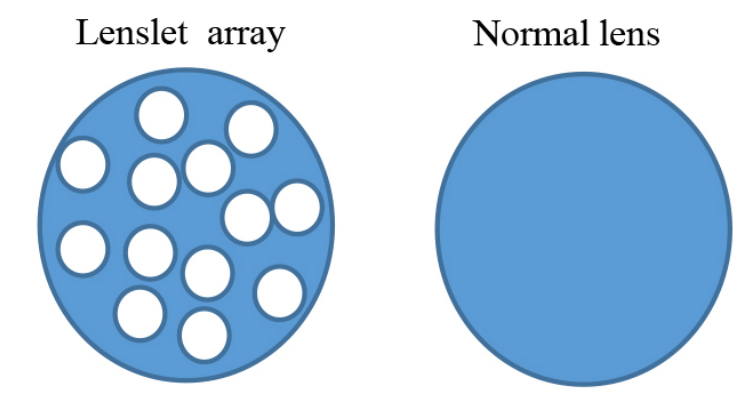

(a) Front view

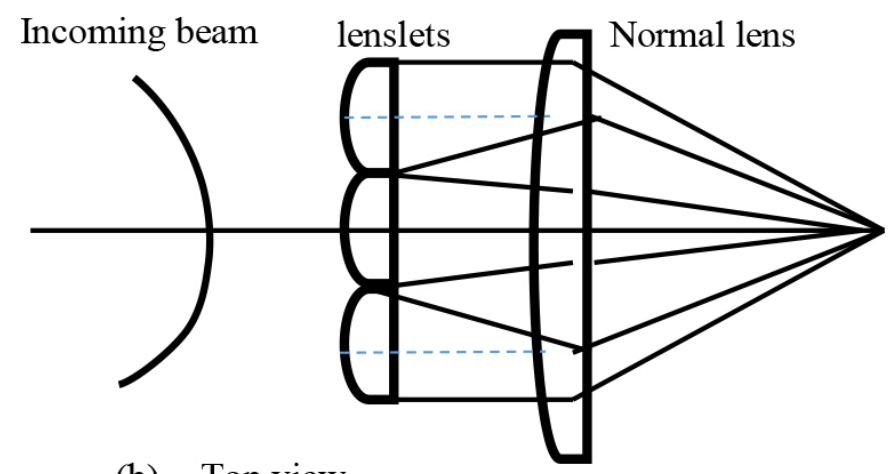

(b) Top view

Fig. 5. (a) Front view, and (b) top view of combination of rotational micro-lens with a normal lens to reduce the temporal crossing of incoming laser radiation and ejected debris in hard-tissue laser ablation.

\section{Influence of laser parameters}

Intensity, wavelength, repetition rate, and duration of laser pulses are the most important parameters influencing the interaction of laser with matters in macroscopic and microscopic scales. In order to perform highly efficient minimal invasive laser surgery and protecting over-heating surrounding tissues, it is important to optimize laser parameters.

\subsection{Laser pulse shape and incidence angle}

Assuming a Gaussian beam energy profile, the following equation applies:

$$
F(r)=F_{0} \exp \left[-2\left(r / w_{0}^{2}\right],\right.
$$

where $\mathrm{F}$ is the fluence at a radial distance $\mathrm{r}$ of the axis of the laser beam, $\mathrm{F}_{0}$ is the peak fluence (at the axis of the laser beam), $\mathrm{w}_{0}$ is the laser beam size. The depth of ablation given by Eq. (6) can be modified for non-normal incidence as $[36,37]$ :

$$
d \simeq \frac{1}{\mu_{a}} \ln \left(\frac{F_{0} \cos \theta}{F_{t h}}\right),
$$


where $\theta$ is the incidence angle. The squared diameter for nonnormal incidence angle [36, 37]:

$$
D^{2}=\frac{4 w_{0}^{2}}{(\cos \theta)^{2}}\left[\frac{1}{2} \ln \left(\frac{F_{0} \cos \theta}{F_{t h}}\right)\right],
$$

For non-normal incidence the spot area of ablation impact is given by $[36,37]$

$$
A=\frac{4 \pi w_{0}^{2}}{(\cos \theta)^{2}}\left[\frac{1}{4} \ln \left(\frac{F_{0}}{F_{\text {th }}}\right) \ln \left(\frac{F_{0} \cos \theta}{F_{\text {th }}}\right)\right],
$$

The volume of ablation impact for non-normal incidence can be calculated as $[36,37]$ :

$$
\begin{aligned}
V & =\frac{\pi w_{0}^{2}}{\mu_{a}^{2}}\left[\ln \left(\frac{F_{0}}{F_{t h}}\right)\right] \\
& \times\left[\frac{1}{2} \ln \left(\frac{F_{0}}{F_{t h}}\right)+\ln (\cos \theta)\right]
\end{aligned}
$$

The optimum spot depth at non-normal incidence can be calculated when

$$
F_{0, o p t}=\frac{F_{t h}}{\cos \theta} e,
$$

which results

$$
d_{\text {opt }}=\frac{1}{\mu_{a}}
$$

The optimum spot diameter at non-normal incidence can be obtained as:

$$
D=\frac{2 w_{0}}{\cos \theta},
$$

The optimum spot area at non-normal incidence can be calculated from:

$$
A=\frac{\pi w_{0}^{2}}{\cos \theta}
$$

The optimum spot volume at non-normal incidence can be calculated from:

$$
\begin{aligned}
V= & \frac{\pi w_{0}^{2}}{\mu_{a} 2}[2-\ln (\cos \theta)] \\
& \times\left\{1+\ln \left[(\cos \theta)^{1 / 2}\right]\right\}
\end{aligned},
$$

\subsection{Laser wavelength}

Wavelength is a key factor in the suitability of any laser for hardtissue procedures in dentistry and osteotomy. Over the last forty years, the most promising laser sources for hard tissue ablation in the infrared spectral region were found to be the $\mathrm{CO}_{2}$ laser $(9.6 \mu \mathrm{m} \& 10.6 \mu \mathrm{m})$, the Er: YAG laser $(2.94 \mu \mathrm{m})$ and the Er: YSGG laser $(2.78 \mu \mathrm{m})$. The Er: YAG and the Er, Cr: YSGG lasers make up the erbium family of dental lasers. When comparing the wavelengths of the erbium doped lasers, the Er: YAG laser's wavelength of $2.94 \mu \mathrm{m}$ matches the absorption peak of water at $2.94 \mu \mathrm{m}\left(12000 \mathrm{~cm}^{-1}\right)$ while the absorption coefficient of water for the $2.78 \mu \mathrm{m}\left(4000 \mathrm{~cm}^{-1}\right)$ wavelength is 3 times lower (see Fig. 6). The difference in the absorption coefficients leads to a difference in the penetration depth in hard tissues.

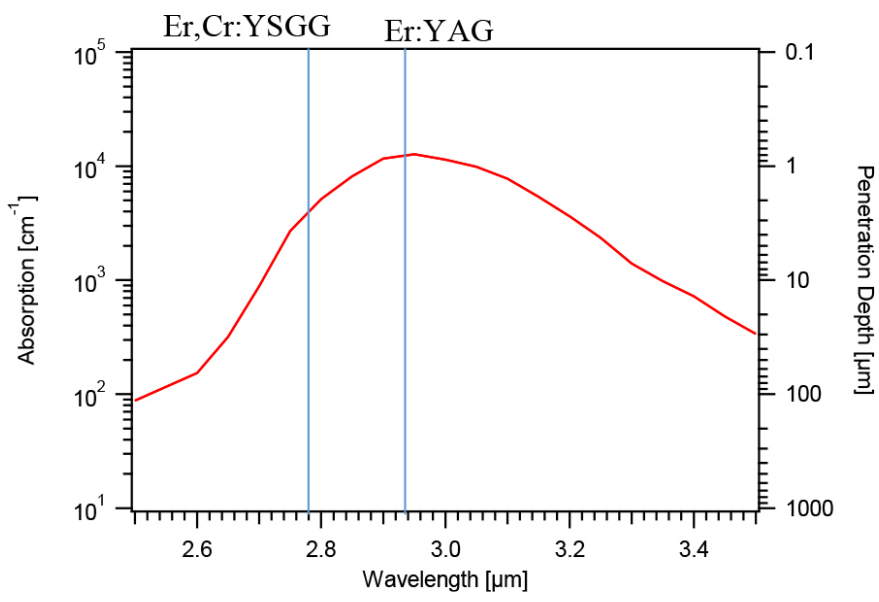

Fig. 6. The absorption curve of water in the middle infrared region. The blue lines show the position Er, Cr: YSGG and Er: YAG lasers. Replotted data from [38].

In the case of relatively large penetration depth, the laser energy may spread out to the surrounding tissues by the process of thermal diffusion before absorption laser energy sufficiently and reach the explosion point that is necessary in thermomechanical ablation process. In other words, the higher the penetration depth, the longer the time required to reach the explosion temperature. For effective ablation hard tissues with minimal thermal side-effects, it is important that the ablation process takes place over a short time so that very little heat is transferred to the surrounding tissues $[39,40]$. Fig. 7 shows that the ablation efficiency of Er: YAG for hard tissue ablation is higher compared to that of Er, Cr: YSGG (see [98] and reference therein). The absorption coefficients of enamel and dentin at $2.94 \mu \mathrm{m}$ is $1500 \mathrm{~cm}^{-1}$ and $2000 \mathrm{~cm}^{-1}$, respectively.

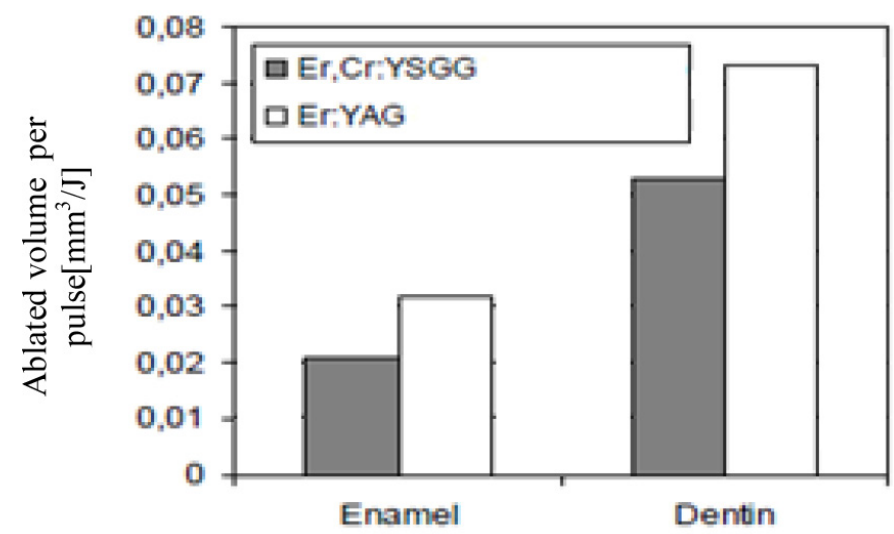

Fig. 7. Ablated volume per pulse energy of dentine and enamel for different laser wavelengths both laser sources at $260 \mathrm{~mJ}$ pulse energy [41].

In contrast to the Er: YAG and Er, Cr: YSGG lasers which operate in the region of the major water absorption, $\mathrm{CO}_{2}$ and $\mathrm{Ho}$ : YAG lasers show significantly lower absorption in water and are thus less suited for treatments in this field. Comparison of the measured ablation speed $\left(\mathrm{mm}^{3} / \mathrm{s}\right)$ for Er: YAG and Er, Cr: YSGG laser shows that ablation speed of dentine and enamel increases linearly with fluence and the 
ablation speed of hard tissue with Er: YAG is always larger compare to that of the Er, Cr: YSGG.

\subsection{Laser fluence and pule width}

Dependence of the ablation threshold in enamel and dentin on the pulse duration and laser type is shown in Fig. 8. The ablation threshold for the shortest SSP $(50 \mu \mathrm{s}) \mathrm{Er}$ : YAG laser pulse is by a factor of 3 lower compared to that of the $\mathrm{H}(500-700 \mu \mathrm{s}) \mathrm{Er}$, Cr: YSGG laser pulse, and by a factor of 6 lower compared to the S $(1600-2000 \mu$ s) Er, Cr: YSGG laser pulse. As expected, ablation threshold increases towards longer pulse durations.

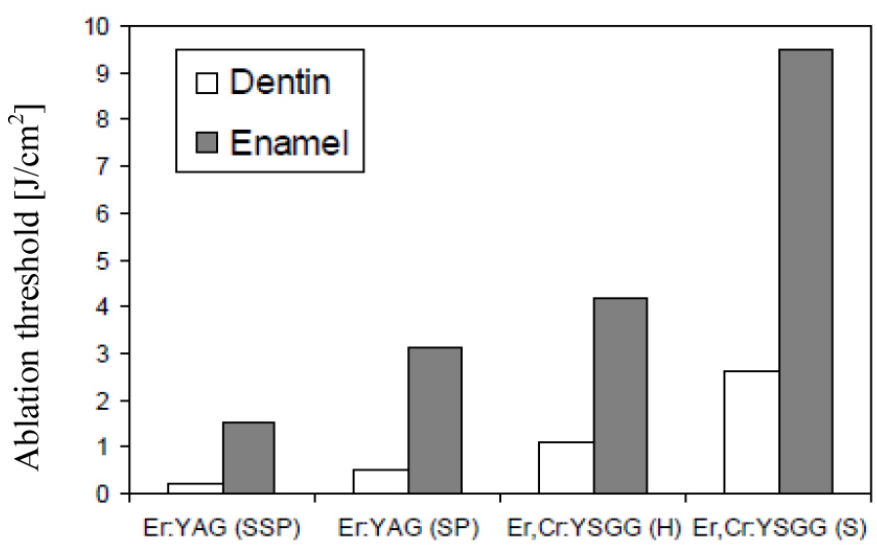

Fig. 8. Dependence of the ablation threshold in enamel and dentin on the pulse duration and laser wavelength [41]

The effect of fluence on ablation diameter is shown in Fig. 9. It can be seen that $\mathrm{D}^{2}$ varies linearly with $\ln \left(\mathrm{E}_{\mathrm{p}}\right)$, where $\mathrm{E}_{\mathrm{p}}$ is energy per, to approve Eq. (9). In this experiment the beam waist radius $\left(\mathrm{w}_{0}\right)$ was $\sim 15$ $\mu \mathrm{m}$ and the ablation thresholds $\left(\mathrm{F}_{\mathrm{th}}\right)$ of dentin and enamel were 1.18 and $1.38 \mathrm{Jcm}^{2}$, respectively. The laser emitted a Gaussian beam with a wavelength of $1.025 \mu \mathrm{m}$, pulse width of $400 \mathrm{fs}$, repetition frequency of 30 to $200 \mathrm{kHz}$, and average power up to $4 \mathrm{~W}$.

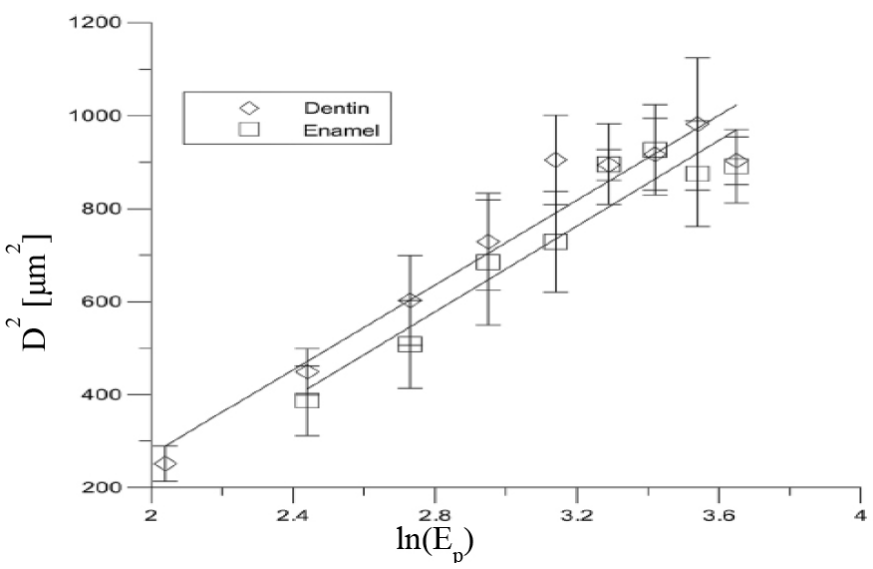

Fig. 9. The squared diameters of the ablated area for dentin and enamel versus natural logarithm of $\mathrm{E}_{\mathrm{p}}[30]$.

Ultrashort pulses ( $<10 \mathrm{ps}$ ) have been shown to generate little thermal or mechanical damage. Thermal effects can be decreased by reducing the pulse duration $[23,24]$ or by using lasers with radiation wavelength in the UV range $[25,26]$. Ablation rate of enamel and dentin as a function of laser fluence with 350 -fs and 1-ns pulses show a clear pattern of saturation near $3 \mathrm{~J} / \mathrm{cm}^{2}$ for both enamel and dentin. With 350 -fs pulses, ablation threshold for dentin was at $0.5 \mathrm{~J} / \mathrm{cm}^{2}$ and for enamel at $0.7 \mathrm{~J} / \mathrm{cm}^{2}$ [24]. In contrast, ablation threshold for dentin with the longer, $1-\mathrm{ns}$ pulses of $1050 \mathrm{~nm}$ was about $20 \mathrm{~J} / \mathrm{cm}^{2}$. A rapid exponential drop in ablation efficiency with increasing fluence was also observed with 350 -fs pulses for both enamel and dentin with a slightly higher efficiency for dentine [24].

Enamel and dentin were also ablated with a 66 fs laser pulses at a wavelength of $800 \mathrm{~nm}$ and a repetition rate of $1 \mathrm{kHz}$ [30]. The focal spot of the laser was $\sim 100 \mu \mathrm{m}$. The initial temperature of the pulpal chamber was $23.6^{\circ} \mathrm{C}$. During the laser ablation process, the temperature rose to a peak value of $35.9^{\circ} \mathrm{C}\left(\Delta \mathrm{T}=12.3^{\circ} \mathrm{C}\right)$. Following the addition of air cooling, the temperature dropped to $26.6^{\circ} \mathrm{C}(\Delta \mathrm{T}$ $=3.0^{\circ} \mathrm{C}$ ). At a laser fluence of $11 \mathrm{~J} / \mathrm{cm}^{2}$ and a scanning velocity of $1 \mathrm{~mm} / \mathrm{s}$, the ablation rates of enamel and dentin were measured to be $5.7 \times 10^{-3} \mathrm{~mm}^{3} / \mathrm{s}$ and $56.0 \times 10^{-3} \mathrm{~mm}^{3} / \mathrm{s}$, respectively. According to [30], the ablation efficiency initially increases almost linearly and then deceases, suggesting that it is possible to find an appropriate fluence value to achieve a maximum ablation efficiency (see Fig. 10). Maximum ablation efficiency of dentin $0.019 \mathrm{~mm}^{3} / \mathrm{J}$ is about 2 times of maximum ablation efficiency of enamel $0.009 \mathrm{~mm}^{3} / \mathrm{J}$. Decreasing ablation efficiency is due to the plasma shielding. Taking into account the maximum ablation efficiency of enamel and $300 \mathrm{~mm}^{3}$ of dental hard tissue, mostly enamel, that is ground out during tooth preparation for a typical full metal crown of a molar, a femtosecond laser with an average power of $\sim 18 \mathrm{~W}$ is required to complete the tooth preparation work within half an hour.

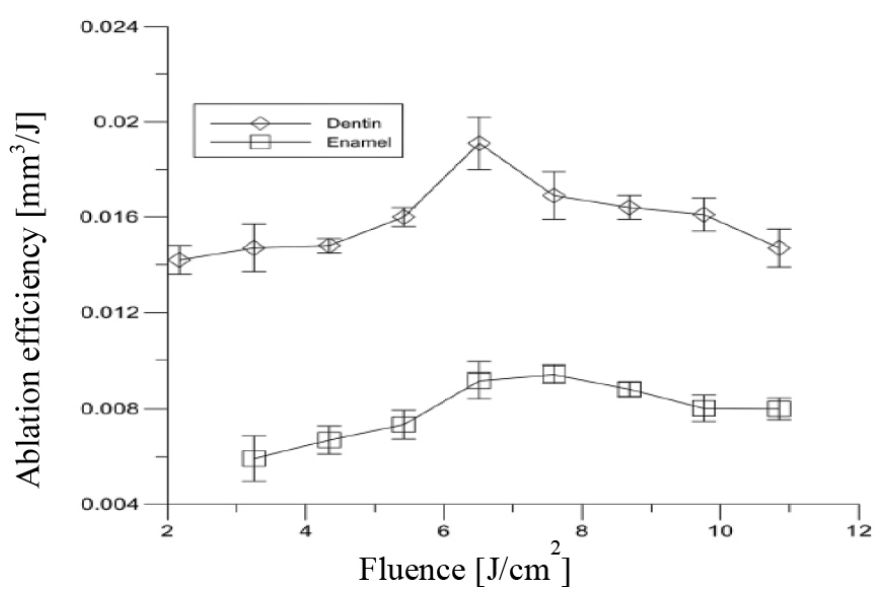

Fig. 10. The ablation efficiency of the ablated area of dentin and enamel versus fluence with a $66 \mathrm{fs}$ laser pulses at a wavelength of $800 \mathrm{~nm}$ and a repetition rate of $1 \mathrm{kHz}$ [30].

It is known that the ablation threshold decreases towards shorter pulse durations. This is due to the fact that for shorter times, the energy has little time to escape from the irradiated volume to the surrounding tissues by heat diffusion to result in faster ablation and smaller amount of residual heat deposition. Fig. 11 shows ablation depths of drilled into dentin (top) and enamel (bottom) with ten consecutive Er: YAG at $2.94 \mu \mathrm{m}$ laser pulses of different duration [39]. With pulse lengths of $100 \mu$ s and $300 \mu \mathrm{s}$, the ablation of dentine starts abruptly at a welldefined fluence value of $4.0 \pm 0.5 \mathrm{~J} / \mathrm{cm}^{2}$.Within the experimental error, 
the ablation threshold is independent of the pulse duration. At higher fluences, the ablation depths increase quasi-logarithmically as a result of absorption and scattering of the laser beam by the ejected debris. The ablation depths of drilled into enamel show qualitatively the same behavior as that in dentin. At the pulse length of $100 \mu \mathrm{s}$, they follow a quasi-logarithmical functional dependence on the applied laser fluence, as predicted by the debris screening model, except for the fluences above $50-70 \mathrm{~J} / \mathrm{cm}^{2}$ where increasingly deeper craters are obtained.
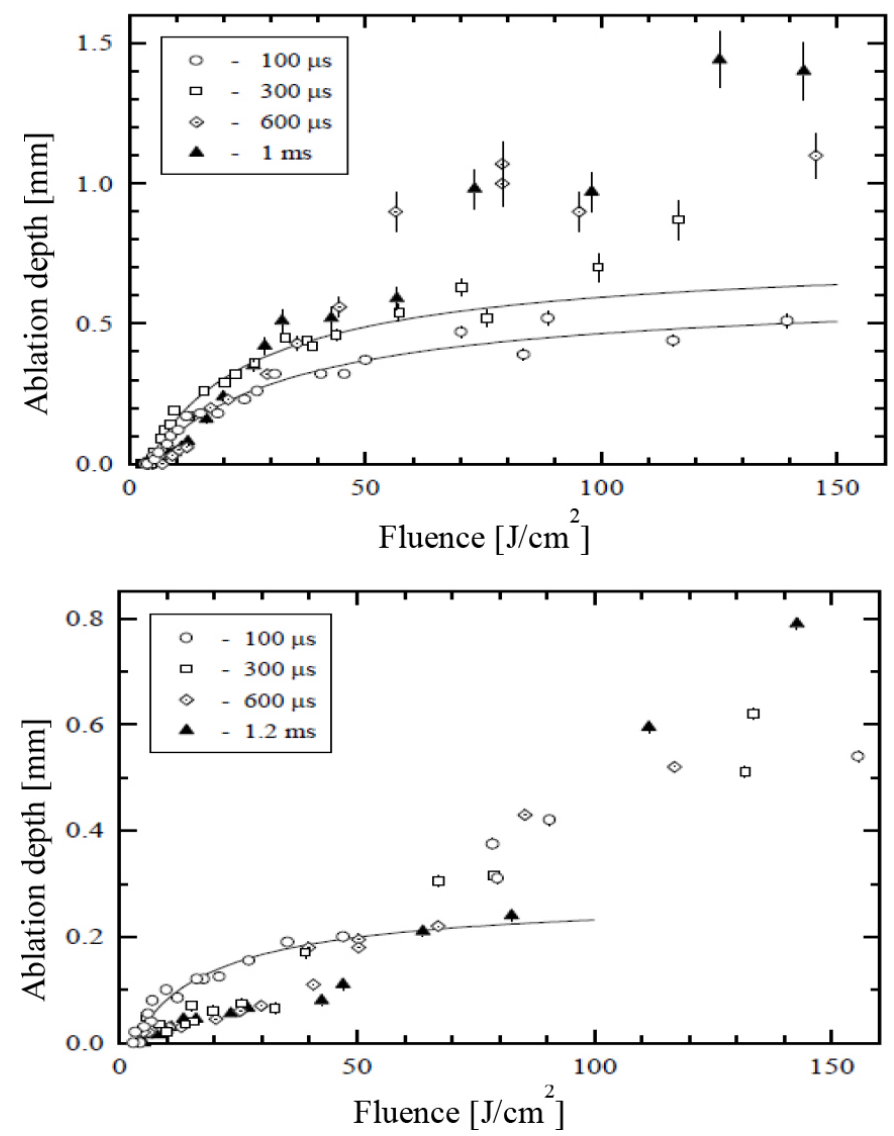

Fig. 11. Ablation depths of drilled into dentin (top) and enamel (bottom) with ten consecutive Er: YAG at $2.94 \mu \mathrm{m}$ laser pulses of different duration (see [39] for details).

\subsection{Water cooling}

The influence of external cooling on the temperature rise in the tooth pulpal chamber during femtosecond laser ablation was investigated. The ablation were performed on dentin using an Yb: KYW which generates a Gaussian 1030-nm radiation wavelength beam with 560 -fs pulse duration [42]. The experiments were performed in air and with surface cooling by a lateral air jet and a combination of an air jet and water irrigation. The ablation rate versus fluence for different cooling methods is plotted in Fig. 15. Independently of the cooling method used, the ablation rate increases linearly with fluence in the range of 2-14 J/ $\mathrm{cm}^{2}$. External cooling has a negligible influence on the ablation rate for fluences in the tested fluence range with fs laser pulses.

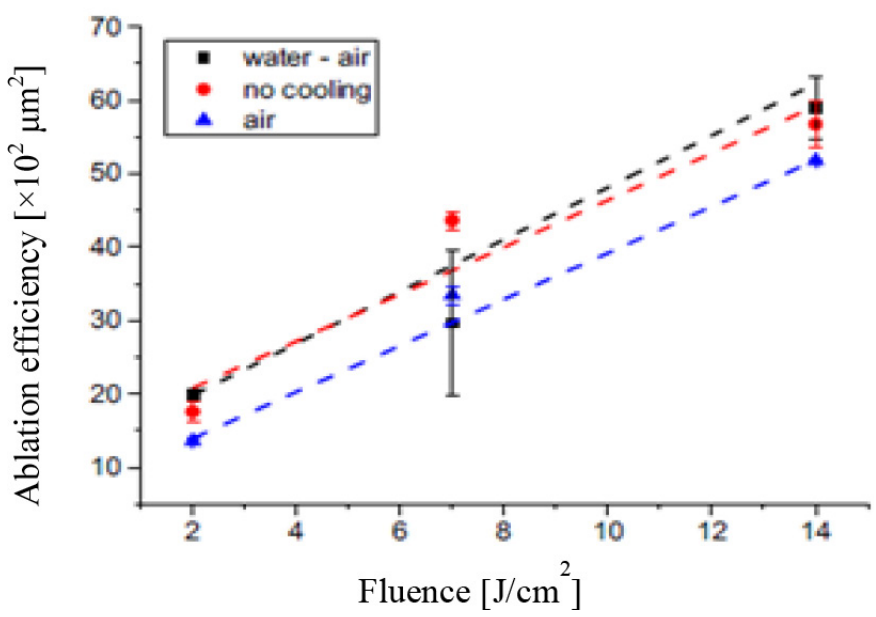

Fig. 12. Ablation rate versus fluence for different cooling methods with1030-nm laser wavelength and 560-fs [42].

The temporal behavior of the pulpal chamber temperature during a laser treatment without external cooling, with an average fluence of $7 \mathrm{~J} / \mathrm{cm}^{2}$ and a pulse repetition rate of $1 \mathrm{kHz}$, is depicted in Fig. 13 [42]. It can be seen that temperature initially increases to reach maximum $34.5^{\circ} \mathrm{C}$ after $65 \mathrm{~s}$, and then remains approximately constant during the full duration up to the end of the laser treatment (175 s). After stopping the laser, the temperature drops almost exponentially with the quiet slow cooling rate due to the low thermal diffusivity of dentin.

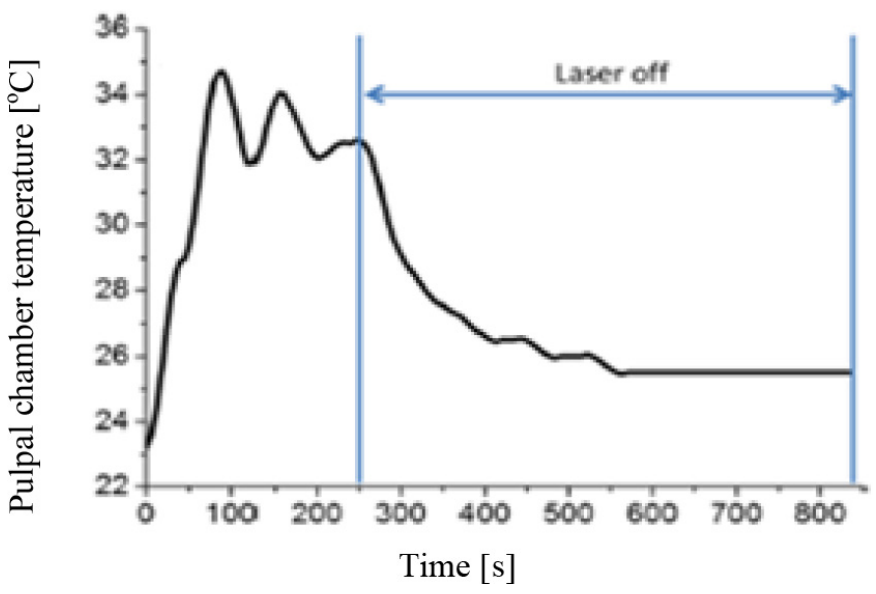

Fig. 13. Dynamic behavior of the pulpal temperature during femtosecond laser irradiation with $7 \mathrm{~J} / \mathrm{cm}^{2}$ [42].

The temperature increases with fluence from approximately 3.1 ${ }^{\circ} \mathrm{C}$ for $2 \mathrm{~J} / \mathrm{cm}^{2}$ to $17.5^{\circ} \mathrm{C}$ for $14 \mathrm{~J} / \mathrm{cm}^{2}$ (Fig. 14). The temperature rise reached $17.5{ }^{\circ} \mathrm{C}$ for the treatments performed with $14 \mathrm{~J} / \mathrm{cm}^{2}$ and without cooling, which was reduced to $10.8 \pm 1.0$ and $6.6 \pm 2.3^{\circ} \mathrm{C}$ with forced air cooling and water cooling, respectively, without significant reduction of the ablation rate.

In addition, the effect of pulse duration on, the ablated dentin by Er: YAG laser at $1 \mathrm{~Hz}$ with a fixed energy at $150 \mathrm{~mJ} /$ pulse corresponding to fluence $\sim 113 \mathrm{~mJ} /$ pulse for three seconds with a water spray (water: $17.6 \mathrm{ml} / \mathrm{min}$; air: $1.21 \mathrm{ml} / \mathrm{min}$ ) has been reported in [43]. As the pulse duration increased, the ablated dentin became deeper but the diameter 
thereof decreased. Figure 15 shows the depth of the cavities after laser irradiation with various pulse durations. As the pulse duration of Er: YAG laser increased, depth of the cavities increased.

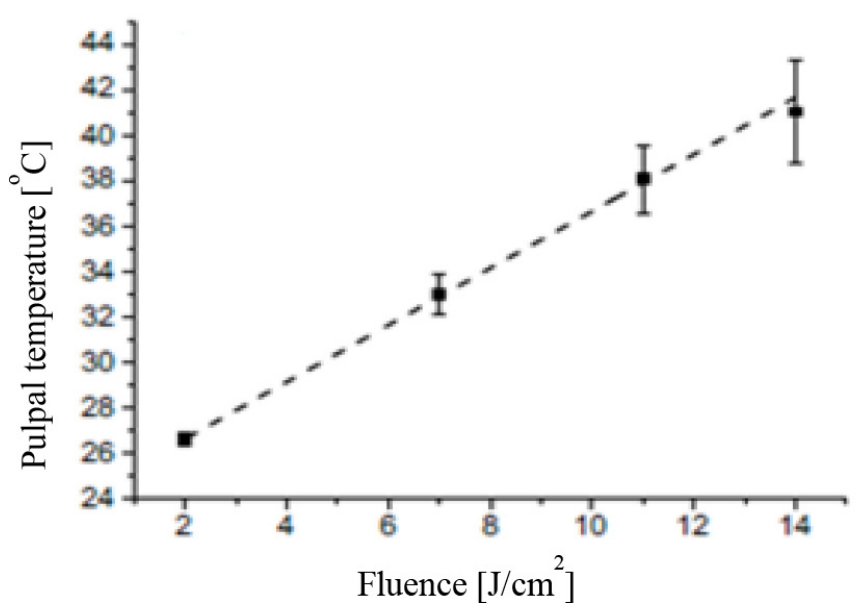

Fig. 14. Maximum temperature of pulpal versus fluence [42].

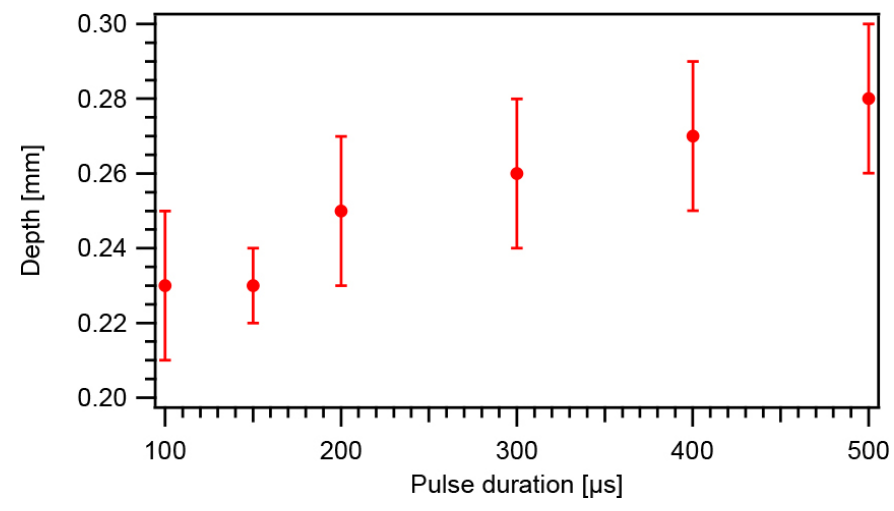

Fig. 15. Depths of ablated dentin after laser irradiation. Reproduced from [43].

Figure 16 shows variation of diameter of the cavities after laser irradiation versus pulse duration. The longer the pulse duration of Er: YAG laser, the smaller the diameter of the irradiated spot.

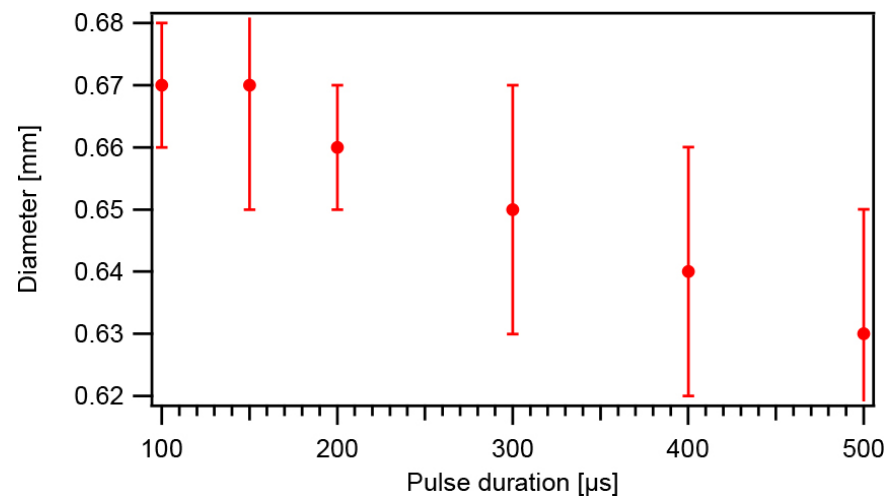

Fig. 16. Diameters of ablated dentin after laser irradiation as a function pulse duration. Reproduced from [43].

As shown in Fig. 17, volume of the cavities did not change statistically with the pulse duration of Er: YAG laser. The average cavity volume following [43] is given by:

$$
V=\pi r^{2} \frac{d}{3} \text {. }
$$

is plotted in Fig. 20 [43].

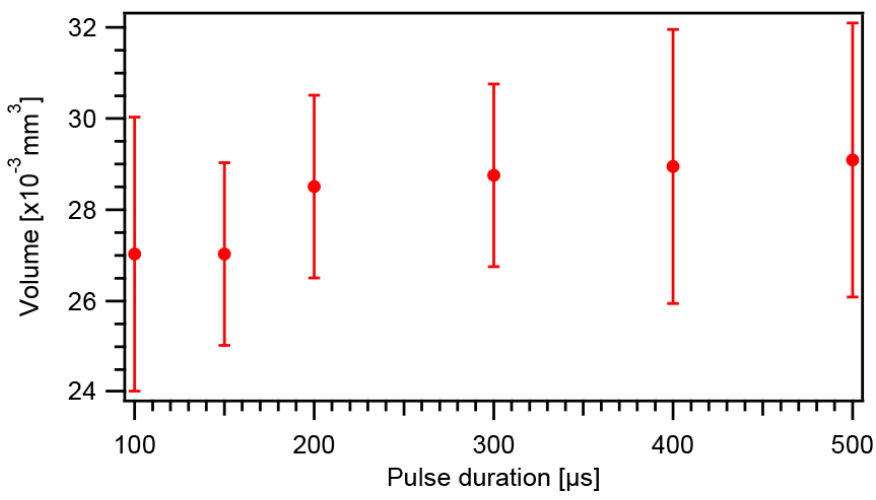

Fig. 17. Estimated volumes of ablated dentin after laser irradiation. Reproduced from [43].

Remarkably different methods have been proposed and investigated for remote monitoring incision depth in laser surgery [44]. Pulsed laser ablation results in vaporization and ejection of tissues, leading to generation of laser-induced shockwaves at the incision spot.

Recently Kušĉer and Diaci [45] measured precisely erbium laserablation efficiency in hard dental tissues under different water cooling conditions. In enamel, the highest $\mathrm{AE}$, with clean cavities and no signs of thermal damage, was observed under the "pores" conditions when the superficial dental tissue was rehydrated only during the time inbetween laser pulses. However, when in addition to the rehydration inbetween the pulses, the pulsed laser beam was intersect with water-spray particles above the tooth ("spray" conditions), or with a water layer on the tooth surface ("pool" conditions), resulted in a reduction of AE.

The effect of pulse duration on reduction of $\mathrm{AE}$ has been also investigated [45]. It was found that spray functions only as an absorber and not as an enhancer of the $\mathrm{AE}$ and this effects gains for longer pulse durations. This can be explained by noting that during longer pulse durations more water is delivered to the tooth, and therefore, more laser energy is required to sustain the vapor tunnel [45]. The relative decrease in $\mathrm{AE}$ due to the presence of spray versus pores, $\mathrm{D}_{\text {spray }}$ as a function of Er:YAG pulse duration is depicted in Fig. 21. As expected, an approximately linear dependence of $D_{\text {spray }}$ on the pulse duration and consequently on the amount of water delivered during the duration of each laser pulse is obtained (see [45] for details).

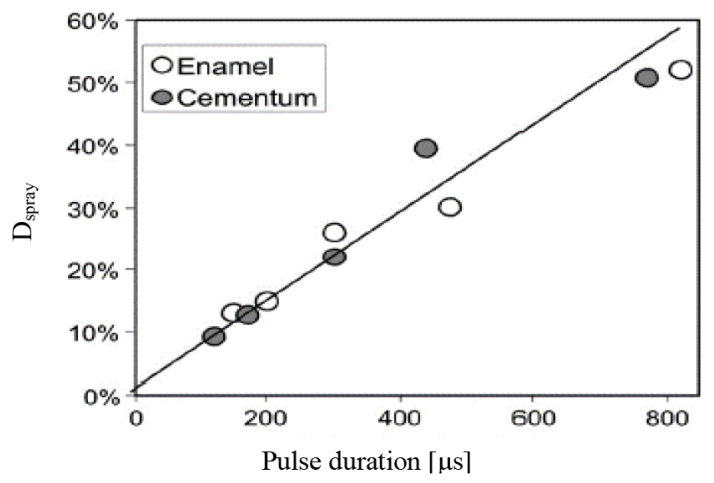

Fig. 18. Relative reduction in $A E, D_{\text {spray }}$ in enamel and in cementum as a function of Er:YAG pulse duration [43]. 


\section{Conclusions}

Non-contact laser surgery presents several advantages such as effectively less damaging surrounding tissues, less pain, less swelling, less bleeding, eliminating trauma, better cutting quality, and high accuracy. However, the cut depth saturates and the ablation efficiency drops with increasing incision depth. This phenomenon is generally found in laser cutting of all kinds of materials. The trend is faster for Gaussian lasers with longer pulse width and smaller beam radius.

Wavelength is a key factor in the suitability of any laser for hard-tissue procedures in dentistry and osteotomy. So far, the most promising laser sources for hard tissue ablation in the infrared spectral region were found to be the $\mathrm{CO}_{2}$ laser $(9.6 \mu \mathrm{m} \& 10.6 \mu \mathrm{m})$, the Er: YAG laser $(2.94 \mu \mathrm{m})$ and the Er: YSGG laser $(2.78 \mu \mathrm{m})$. The Er: YAG and the Er, Cr: YSGG lasers make up the erbium family of dental lasers. When comparing the wavelengths of the erbium doped lasers, the Er: YAG laser's wavelength of $2.94 \mu \mathrm{m}$ matches the absorption peak of water at $2.94 \mu \mathrm{m}\left(12000 \mathrm{~cm}^{-1}\right)$ while the absorption coefficient of water for the $2.78 \mu \mathrm{m}\left(4000 \mathrm{~cm}^{-1}\right)$ wavelength is 3 times lower. The difference in the absorption coefficients leads to a difference in the penetration depth in hard tissues.

Er: YAG lasers are currently in use for dental hard tissue ablation in clinical practice. Ablation is accomplished through the localized laser-induced generation of heat. However, as the pulse width of the laser is increased, the thermal effect becomes more obvious, producing significant collateral damage in the target area (e.g., microcracking, carbonation and melting).

Femtosecond lasers, unlike Er: YAG lasers, use ultrashort pulses. When the pulse width is shorter than the target material's thermal relaxation time, thermal diffusion cannot take place, and strong peak power can ionize the material into plasma, thus greatly reducing the generation of thermal effects and collateral damage. Indeed, cold ablation processing can be attained with high accuracy and almost no effect on the vitality of the pulp. When the excitation time is shorter than the thermalization time in the material, non-thermal, photochemical ablation mechanisms can occur. It induces a clean ablation of tissue without thermal effects.

In general, thermal effects can be decreased by reducing the pulse duration or by using lasers with radiation wavelength in the UV range. At shorter times, the energy has little time to escape from the ablated volume, and so less heat is diffused into the surrounding tissue. Lasers that produce a photothermal effect use prolonged energy exposure to facilitate an increase in chromophore temperature, which in turn leads to cellular vaporization. On the other hand, short laser pulses are expected to produce higher-frequency tissue vibrations and may therefore cause more discomfort to patients.

However, strong absorption and scattering of incoming laser beam by dense debris cloud above the irritated area results a reduced ablation rate. The scattering effect caused by the debris cloud leads to spreading out the laser beam and therefore less precise the cut geometry. The laser reheats the debris and it falls back to the tissue surface to additional heating the tissue and consequently reducing the ablation rate and additional residual heat deposition.
A quantum square pulse (QSP) chopped long pulses in NIR region makes it possible to significantly increase dental enamel and cementum ablation drilling efficacy and reduce the rate of tissue desiccation with decreasing temporal crossing of incoming laser radiation and ejected debris. However, chopper wheel blocks the laser light to result modulation of laser beam with the expense of energy loss. An alternative novel method to reduce the temporal crossover of incoming laser radiation with ejected debris is combination of rotational micro-lens with a normal lens which focuses the laser light on the bone tissue sample. In this method an array of rotational micro-lens which is combined with a normal lens focuses the laser light on the hard tissue sample to increase the ablation efficiency in incision depth by creating channels in laser beam and reducing the effect of interaction laser and debris and therefore ejecting debris with less interaction with laser light. Consequently, the absorption and scattering of the incoming laser light by the debris decreases even with rising cut depth and thereby most of the energy can reach the depth of the incision.

\section{References}

1. A.R. Eriksson, T. Albrektsson, B. Albrekisson, (1984) Heat caused by drilling cortical bone. Acta Orthop. Scand, 55: p. 629. [Crossref]

2. P. D. Gabrić, et al., (2012) Comparison of Er: YAG Laser and Surgical Drill for Osteotomy in Oral Surgery: An Experimental Study. J Oral Maxillofac Surg, 70: p. 2515-2521. [Crossref]

3. A. Troedhan, et al., (2017) Cutting bone with drills, burs, lasers and piezotomes: A comprehensive systematic review and recommendations for the clinician. Int J Oral Craniofac Sci 3: p. 020-033. [Crossref]

4. S. Toksvig-Larsen, L.Ryd, A. Lindstrand, (1992) Temperature influence in different orthopaedic saw blades. J. Arthroplasty, 7: p. 21-24. [Crossref]

5. S. Toksvig-Larsen, L.Ryd, A. Lindstrand, (1992) Temperature influence in different orthopaedic saw blades. J. Arthroplasty, 7: p. 21-24. [Crossref]

6. Y. Zhang, C.Wang, S. Zhoua, W. Jiang, Z. Liu, L. Xu, (2017) A comparison review on orthopedic surgery using piezosurgery and conventional tools. Procedia CIR, 65: p. 99-104. [Crossref]

7. U. Romeo, A. D. Tenore, P. Visca, C. Maggiore, (2009) Bone damage induced by different cutting instruments - an in vitro study. Braz Dent J. 20: p. 162-168. [Crossref]

8. M. Frentzen, W. Goetz., M. Ivanenko, S. Afilal, M. Werner, P. Hering, (2003) Osteotomy with $80 \mu \mathrm{s}$ CO2 laser pulses - histological results. Laser Med. Sci., 18: p. 110-124. [Crossref]

9. S. R. Visuri, J. T. Walsh, and H. A. Wigdor, (1996) Erbium Laser Ablation of Dental Hard Tissue: Effect of Water Cooling. Lasers in Surgery and Medicine, 18: p. 294 300. [Crossref]

10. A. Vogel, and V. Venugopalen, (2003) Mechanisms of pulsed laser ablation of biological tissues'. Chem. Rev, 103: p. 577-644 [Crossref]

11. D. Fantarella, and L. Kotlow, (2014) The 9.3- $\mu \mathrm{m} \mathrm{CO2} \mathrm{Dental} \mathrm{Laser:} \mathrm{Technical}$ Development and Early Clinical Experiences. J. Laser Dent. 22: p. 10-27. [Crossref]

12. R .J. Wallace, C. J. Whitters, J. A. McGeough, A. Muir, (2004) Experimental evaluation of laser cutting of bone. J.of Materials Processing Technology 149 (2004) 557-560, 149: p. 57-560. [Crossref]

13. G. M. Hale, M. R. Querry, (1973) Optical constants of water in the 200-nm to 200$\mu \mathrm{m}$ wavelength region. Appl. Opt., 12: p. 55-563. [Crossref]

14. R. Hibst, U. Keller, (1989) Experimental studies of the application of the Er: YAG laser on dental hard substances: I. Measurement of the ablation rate. Lasers in Surgery and Medicine. 9: p. 338-344. [Crossref]

15. E. Kilinc, D. M. Roshkind, S. A. Antonson, D. E. Antonson, P. C. Hardigan, et al., (2009) Thermal safety of Er: YAG and Er,Cr: YSGG lasers in hard tissue removal. Photomedicine and Laser Surgery, 27: p. 565-570. [Crossref]

16. G. M. Peavy, L. Reinisch, J. T. Payne, V. Venugopalan, (2009) Comparison of cortical bone ablations by using infrared laser wavelengths 2.9 to $9.2 \mu \mathrm{m}$. Lasers Surg Med., 1999. 25: p. 421-34. [Crossref]

17. M. Ivanenko, R. Sader, S. Afilal, M. Werner, M. Hartschock, et al., (2005) In-vivo animal trials with a scanning CO2 laser osteotome. Lasers Surg. Med., 37: p. 144148. [Crossref] 
18. M. Ivanenko, M. Werner, S. Afilal, M. Klasing, P. Hering, (2005) Ablation of hard bone tissue with pulsed CO2 lasers. Med. Laser Appl., 20: p. 13-25. [Crossref]

19. C. Parrilla, J. Galli, A. R. Fetoni, M. Rigante, G. Paludetti, (2008) Erbium: yttriumaluminum-garnet laser stapedotomy-A safe technique. Otolaryngology - Head and Neck Surgery, 138: p. 507-512. [Crossref]

20. M. H. Niemz, (2007) Laser-Tissue Interactions: Fundamentals and Applications. Springer-Verlag Berlin Heidelberg: Springer. [Crossref]

21. C. Garban-Labaune, et al., (1982) Effect of Laser Wavelength and Pulse Duration on Laser-Light Absorption and Back Reflection. Appl. Phys. Lett., 48: p. 10181021. [Crossref]

22. D. Fried, R. E. Glena, J. D. B. Featherstone, W. Seka, (1997) Permanent and Transient Changes in the Reflectance of CO2 Laser-Irradiated Dental Hard Tissues at lamda $=9.3,9.6,10.3$, and $10.6 \mu \mathrm{m}$ and at Fluences of 1-20 J/cm2 Lasers in Surgery and Medicine, 20: p. 22-32. [Crossref]

23. S. Alves, V. Oliveira, and R Vilar, (2012) Femtosecond laser ablation of dentin. $J$ Phys. D: Appl. Phys., 45: p. 245401. [Crossref]

24. J. Neev, L. B.Da .Silva, M. D. Feit, M. D. Perry, A. M. Rubenchik, and B. C. Stuart, (1995) Ultrashort pulse lasers for hard tissue ablation. IEEE Journal of Selected Topics in Quantum Electronics, 2: p. 790-800. [Crossref]

25. F. Sanchez, A. J. Espana Tost, and J. L. Morenza, (1997) ArF excimer laser irradiation of human dentin. Lasers Surg. Med., 21: p. 474-479. [Crossref]

26. S. Eugenio, M. ivakumar., R. Vilar, A. M. Rego, (2005) Characterisation of dentin surfaces processed with $\mathrm{KrF}$ excimer laser radiation. Biomaterials, 26: p. 67806787. [Crossref]

27. M. J. C. van Gemert, and A. J. Welch, (1989) Clinical use of laser-tissue interactions. IEEE Engineering in Medicine and Biology Magazine, 8: p. 10-13. [Crossref]

28. Q. Feng, Y. N. Picard, H. Liu, S. M. Yalisove, G. Mourou, T. M. Pollock, 2005) Femtosecond laser micromachining of a single-crystal superalloy. Scripta Materialia, 52: p. 511-516. [Crossref]

29. S. Baudach, J. Bonse, and W. Kautek, (1999) Ablation experiments on polyimide with femtosecond laser pulses. Appl. Phys. A, 69: p. S395-S398. [Crossref]

30. H. Chen, J. Liu, H. Li, W. Ge, Y. Sun, Y. Wang, and P. Lü, (2015) Femtosecond laser ablation of dentin and enamel: relationship between laser fluence and ablation efficiency. Journal of Biomedical Optics, 20: p. 028004. [Crossref]

31. J. Krüger, W. Kautek, and H. Newesely, (1999) Femtosecond-pulse laser ablation of dental hydroxyapatite and single-crystalline fluoroapatite. Appl. Phys. A, 69: p. S403-S407. [Crossref]
32. R. F. Z. Lizarelli, M. M. Costa, E. Carvalho-Filho, F. D. Nunes, and V. S. Bagnato, (2008) Selective ablation of dental enamel and dentin using femtosecond laser pulses. Laser Phys. Lett., 5: p. 63-69. [Crossref]

33. A. J. Cox, A. J. DeWeerd, and J. Linden, (2002) An experiment to measure Mie and Rayleigh total scattering cross sections. Am. J. Phys., 70: p. 620-625. [Crossref]

34. M. I. Skolnik, (2001) Introduction to radar systems (3rd Ed.). New Delhi, India: McGraw Hill, Inc. [Crossref]

35. N. Lukac ${ }^{\nu}$ T. Suhorrsnik, M. Lukac ${ }^{`}$, and M. Jezeršeka, (2016) Ablation characteristics of quantum square pulse mode dental erbium laser. Journal of Biomedical Optics, 21: p. 015012. [Crossref]

36. S. Arba-Mosquera, and D. de Ortueta, (2008) Geometrical analysis of the loss of ablation efficiency at non-normal incidence. Opt. Express, 6: p. 3877-3895. [Crossref]

37. S. Arba-Mosquera, and S. Verma, (2013) Analytical optimization of the ablation efficiency at normal and non-normal incidence for generic super Gaussian beam profiles. Biomed. Opt. express, 4: p. 1422-1433. [Crossref]

38. G. M. Hale, and M. R. Querry, (1973) Optical Constants of Water in the 200-nm to 200-um Wavelength Region. App. Opt., 12: p. 555-563. [Crossref]

39. B. Majaron, B. Sustersic, M. Lukac, U. Skaleric, and N. Funduk,(1998) Heat diffusion and debris screening in Er: YAG laser ablation of hard biological tissues. Appli. Phys. B, 66: p. 1-9. [Crossref]

40. T. Perhavec, M. Lukac, J. Diaci, M. Marincek, (2009) Heat deposition of erbium lasers in hard dental tissues. J. Oral Laser Appl, 9: p. 205-212. [Crossref]

41. T. Perhavec, and J. Diaci, (2008) Comparison of Er: YAG and Er, Cr: YSGG dental lasers. J. Oral Laser Appl, 8: p. 87-94. [Crossref]

42. Q. T. Le, R. Vilar, and C. (2015) Bertrand, Influence of external cooling on the femtosecond laser ablation of dentin. Lasers Med. Sci., p. DOI 10.1007/s10103017-2277-8. [Crossref]

43. Y. Nishimoto, et al., (2008) Effect of pulse duration of Er: YAG laser on dentin ablation. Dent. Mater J., 27: p. 433-439. [Crossref]

44. F. J. O. Landa, X. L. Dean-Ben, F. Motero de Espinosa, and D. Razansky, (2008) Noncontact monitoring of incision depth in laser surgery with air-coupled ultrasound transducers. Optics Letters, 2016 41: p. 2704-7. [Crossref]

45. L. Kuscer, and J. Diaci., (2013) Measurements of erbium laser-ablation efficiency in hard dental tissues under different water cooling conditions. Journal of Biomedical Optics, 18: p. 108002. [Crossref]

\section{Citation:}

